\title{
An investigation on Challenges in the Implementations of Literary Components in English classroom
}

\author{
Tsegaye Abie Gebeyehu \\ Assistant Professor in English Literature, Wachemo University, Ethiopia \\ Berhanu Erchafo Mengesha \\ Senior Lecturer in TEFL, Wachemo University, Ethiopia
}

\begin{abstract}
This study mainly focused on an investigation of challenges in the implementations of literary components in English classroom. The study was basically conducted at Ambicho Gode Primary School Grade Eight students in particular. Data, to achieve this study, were collected with questionnaire, semi-structured interview and textual analysis. To conduct this research, random and available sampling techniques were employed to select sample students and sample English language teachers respectively. The findings of the study shows that the basic challenges in the implementations of literary components are students' lack of motivation to learn, complexity of language employed in the production of literary components, the medium of instruction, lack of trainings for English teachers, absence of sufficient imaginative works in the library, time allotted for the lessons or the curriculum designed for the text, large classroom size, etc. The text is designed different poems, role plays, flash fictions, non-fictional writings like biographies of prominent persons, piece of oral traditions like fables, folktales and Essay writings such as narrative, expository and descriptive types etc.
\end{abstract}

Keywords: literature, components, challenges and implementation

DOI: $10.7176 / \mathrm{JLLL} / 69-01$

Publication date:June 30th 2020

\section{Introduction}

In the $19^{\text {th }}$ century, literature was considered as it plays a very important role in EFL teaching. The purpose of FLT is to read and appreciate literature. However, EFL teaching paradigm was changed by emphasizing that EFL teaching was Oral Communication. Hence, literature was ignored in teaching EFL. However, after the past two decades, new image was created regarding to immense role of literature in EFL teaching. As a result, literature as found its way back into the teaching of EFL as one of main course material. It was too considered as authentic, fun; reinforce language skills, character building, developing high-order thinking skills, cultural knowledge, and universal values.

Since the middle of 1980 s, literature was reappraised due to considerations on its feasible applications in EFL classes after being neglected for a long period of time. This is witnessed by the expression of Maley (1989) as cited in Cao, H.P, (n.d)) that he stated as literature is back but wearing different clothes. This was also supported by Cairney (1988) as cited in Cao, H.P, (n.d)) that literature was not and should not be seen as add-on but should represent the very heart and soul of the language curriculum. In teaching a foreign language just like Ethiopia, it is indispensable that the teachers should integrate literary texts as literature is a wonderful resource for enhancing and developing the learner's linguistic competence. On the other hand, the study of literature is fundamentally a study of language in operation and literature can fit into virtually any language methodology. (Moody (1971) as cited in Cao, H.P, (n.d))

On the other hand, Lazar (1993) asserts that literature in the EFL classroom develops language acquisition, expands language awareness, offers access to cultural background, reinforces student's interpretative abilities and educates the whole person in so far as it enhances the learner's imaginative and affective competences. In other words, literature may well raise awareness of other cultures, enhance literary competences and evolve language mastery. Lazar (1993: 19) also says that 'Literature is a particularly good source for developing students' abilities to infer meaning and to make interpretations. This is because literary texts are often rich in multiple levels of meaning, and demand that the reader/learner is actively involved in 'teasing out' the unstated implications and assumptions of the text." Similarly, she maintains that "literature may also have a wider educational function in the classroom in that it can help to stimulate the imagination of our students, to develop their critical abilities and to increase their emotional awareness (Ibid, 21).

Carter \& Long, (1991) on the other hand pinpoints as the teaching of literature in EFL classes is essential and can be used as a perfect instrument to stimulate and speed up the teaching and learning process. Similarly, Burke and Brumfit (1986) as cited in Ghouti \& Mohammed (2014) state that literature promotes literacy and critical and analytical ability, social skills and the use of the imagination; inspires learners with open-minded, ethical and humanitarian attitudes, respect cultural tradition; and provide information about literature and language. It, in fact, requires learners to explore and interpret the social, political, literary and historical context of a specific text. 
Van (2009) as cited in Yeasmin, et al (2011) in a research shows the relevance and efficacy of using literature with right approach for language learners arguing that the use of literary text with apt theoretical approach can make it more effective for the EFL classroom. He also states that literature activates students' schemata and personalizes the learning experience that increases their participation and motivation. It encourages language learning through student-centered and process-oriented activities (ibid). Similarly, Alam (2007) cited in Yeasmin, et al (2011) maintains that literary texts stimulate the imagination, offer learners specimens or samples of real language use, allow for group discussions and individual exploration, and are intrinsically more dialogic.

Literature is one of the teaching materials that can help students in the foreign language learning process. Literary works can be regarded as a source of additional practice. They can provide students with lessons on grammar, vocabulary and other kinds of linguistic exercises. Hence, literature can help students in the language learning process and help them enhance their general linguistic knowledge (Shazu, 2014 as cited in Atefeh Rezanejad et al (2015)).

Though scholars stated various advantages of literature in EFL classroom, some scholars on the other hand justified their views on the cons of implementing the literary component in the language classroom. Rivers (1981) and Littlewood (1986) as cited in Kheladi Mohammed, (2013) state that literature is an uncertain business and devaluate its role as a source for language learning/teaching. Littlewood (1986) as cited in Kheladi Mohammed, (2013) states as there is at present a high degree of uncertainty about the role of literature in a foreign language course. Rivers (1981) as cited in Kheladi Mohammed, (2013) pinpoints as literature is imagination; as a result, it does not reveal the true picture of the target language community. In addition, Savvidou (2004) as cited in Kheladi Mohammed, (2013) states as literature may appear strange to foreign learners because it is highly culturally charged; hence, it would be difficult for them to grasp the conceptual notions that literature embodies.

Moreover, from the linguistic standpoint, literary texts are believed to be unsuitable as a model for teaching / learning the language. They are loaded with unfamiliar vocabulary and complex syntax structure (MaKay, (1986) as cited in Kheladi Mohammed, (2013)), and this may pose immense hurdles for the foreign language learner in comprehending them. She also notes that the study of literature will contribute nothing to helping our students meet their academic and/or occupational goals.(Ibid).

Furthermore, Hall (2005) as cited in Kheladi Mohammed, (2013) dismisses the role of literature in language acquisition in the ELT context. He pinpoints that if language is logically to be at the center of the language syllabus, literature syllabuses for language learners failed to engage with or at least to explicitly signal their relevance to language acquisition and language skills. Hall's claim is based on the fact that the language of literature is far from the everyday language that foreign language learners need for practical communicative ends.

In Ethiopian context, English is given as a foreign language and it serves as a medium of instruction in the country. As a result, different literary components were incorporated in the English Language syllabus with numerous aims. Including these literary components in the text books or syllabus has various advantages. Firstly, literary components help to inculcate the reading habit among students and to enrich students' vocabulary and language content and to improve English language proficiency of them. It also aims to enable learners to engage in a wider reading of good works and for enjoyment and self-development and develop an understanding of other societies, cultures, values and traditions that will contribute to their emotional and spiritual growth. On the other hand, they help to enhance students' thinking skills and promote cultural understanding or share unfamiliar cultures. Though the inclusion of these literary components has advantages, there are various challenges challenging both teachers and students in their implementations. Therefore, this study seeks to investigate the basic challenges both teachers and students encounter in the course of practicing the literary components in the English classroom.

\section{Objectives of the study}

This study mainly aimed at assessing basic challenges in practicing literary components in English class room: In Case of Grade Eight at Ambicho Gode Primary School. Specifically, this research attempted to identify challenges affecting both teachers and students in practicing literary components in the class room and to know the literary components employed in the syllabus.

\section{Methodology of the Research}

This study was designed to be mixed approach since both qualitative and quantitative research methods were employed. The researchers employed available sampling technique to select sample teachers. As a result, two English teachers were taken as samples of this study. On the other hand, simple random sampling technique was employed to select sample students. From the total number of 154 of grade 8 students, 30 students were randomly taken as samples of this study.

To obtain relevant information, the researchers collected data from primary sources (questionnaire and interview) and secondary sources like research articles, online sources, journals, and published and unpublished sources. Questionnaire was used to gather data from students related to basic challenges in the practice of the literary components in English class room. The questionnaire contains both close and open ended questions. The 
questionnaires were distributed to 30 students what problems they face in the practice literary components in English classroom. On the other hand, two teachers were taken for semi- structured interview to understand their views related to the study under scrutiny. Document analysis that is Grade Eight English Text Book was also used as a source for reviewing what literary components are employed in the syllabus. And lastly, the data were analyzed both in quantitatively and qualitatively.

\section{Analysis and Interpretation of Data}

\subsection{Analysis of the Questionnaire Data}

1: Students' lack of interest for the lesson as challenge

\begin{tabular}{|l|l|l|l|l|}
\hline No. & Item & Option & No- of respondents & Percentage (\%) \\
\hline \multirow{3}{*}{$\begin{array}{l}\text { Students' lack of } \\
\text { interest }\end{array}$} & very high & 11 & $36 \%$ \\
\cline { 3 - 5 } & High & 4 & $13 \%$ \\
\cline { 3 - 5 } & Neutral & 2 & $6 \%$ \\
\cline { 3 - 5 } & & Low & 4 & $13 \%$ \\
\cline { 3 - 5 } & very low & 9 & $30 \%$ \\
\cline { 3 - 5 } & & Total & 30 & $100 \%$ \\
\hline
\end{tabular}

As shown above, $36 \%$ and $13 \%$ of respondents responded that students' lack of interest is very high and high respectively challenging factor in the practice of literary works in English classroom. This shows that students are not motivated to read literary components entertained in the text. This might be because of the language utilized in the production of literary components and the nature of them too; however the $30 \%$ and $13 \%$ of the respondents' interest is very low and low in practice of literary works respectively. $6 \%$ of respondents are neutral in relation to their interest. To wrap up this, students' lack of interest is a serious challenge for practicing literary works in English classroom. This may create a problem in achieving the overall aims of the lesson depicted in the curriculum.

\section{2: Language used in literary components as a challenge}

\begin{tabular}{|l|l|l|l|l|}
\hline No- & Item & Option & No- of respondents & Percentage $\%$ \\
\hline 7 & \multirow{4}{*}{$\begin{array}{l}\text { Language used in } \\
\text { literary }\end{array}$} & Very high & 9 & $30 \%$ \\
\cline { 2 - 5 } & High & 14 & $47 \%$ \\
\cline { 3 - 5 } & Nemponents & 0 & $0 \%$ \\
\cline { 3 - 5 } & Low & 4 & $13 \%$ \\
\cline { 3 - 5 } & Very low & 3 & $9 \%$ \\
\cline { 3 - 5 } & Total & 30 & $100 \%$ \\
\hline
\end{tabular}

As depicted in the above table, $47 \%$ and $30 \%$ of the respondents responded that the language used in literary works is both very high and highly challenging factor in the implementation of literary components in English classroom respectively. This shows how much defamiliarized language is utilized in the production of the literary components implemented in the classroom. The complexity of the language in its form and meaning makes the literary components complicated to students so as to understand what is depicted in it. On the other hand, $14 \%$ and $9 \%$ of respondents responded that the language used in literary components is low and very low. This implies that in some extent some students can understand the language used in the literary components. Generally, the language used in the literary components is a challenge for students not to understand the messages of literary components; but some students are interested with the language used in it.

\section{Teachers' academic performance as a challenge}

\begin{tabular}{|l|l|l|l|l|}
\hline No- & Item & Option & No- of respondents & Percentage (\%) \\
\hline 2 & \multirow{2}{*}{$\begin{array}{l}\text { Teachers' academic } \\
\text { performance }\end{array}$} & very high & 7 & 24 \\
\cline { 3 - 5 } & & High & 6 & $20 \%$ \\
\cline { 3 - 5 } & Neutral & 8 & $26 \%$ \\
\cline { 3 - 5 } & & Low & 5 & $16 \%$ \\
\cline { 3 - 5 } & & very low & 4 & $14 \%$ \\
\cline { 3 - 5 } & & Total & 30 & $100 \%$ \\
\hline
\end{tabular}

As seen above, $24 \%$ and $20 \%$ of respondents responded that teachers' academic performance is a very high and high challenging factor in the practice of literary works in English classroom respectively. This implies that teachers need to have trainings on the concept of literary components and their roles and implementations in the language classroom. $16 \%$ and $14 \%$ of respondents responded as teachers' academic performance has low and a very low impact in the practice of literary works in English classroom respectively. This, on the other hand, implies, in some extent, teachers have the know-how and the ability on how to implement the literary components found in the text book. $26 \%$ of respondents replied as they are not sure whether teachers' academic performance is a challenge or not in the practice of literary works in English classroom. Based on these, we can conclude that teachers' academic performance is a challenge in practicing literary works in English classroom or teachers are 
unable to implement the literary components.

4. Large Classroom size as a challenge

\begin{tabular}{|l|l|l|l|l|}
\hline No- & Item & Option & No- of respondents & Percentage (\%) \\
\hline \multirow{3}{*}{3} & \multirow{2}{*}{ Large classroom size } & very high & 9 & $30 \%$ \\
\cline { 3 - 5 } & & High & 7 & $24 \%$ \\
\cline { 3 - 5 } & Neutral & 5 & $16 \%$ \\
\cline { 3 - 5 } & Low & 4 & $14 \%$ \\
\cline { 3 - 5 } & & very low & 5 & $16 \%$ \\
\cline { 3 - 5 } & Total & 30 & $100 \%$ \\
\hline
\end{tabular}

As explained above, $30 \%$ and $24 \%$ of respondents responded that classroom size has a very high and high impact in the practice of literary works in English classroom respectively. On the other hand, $14 \%$ and $16 \%$ of respondents responded that the classroom size has a low and a very low side effect in the practice of literary works. $16 \%$ of respondents replied as they are neutral of it. So, in Ambicho Gode primary school, the classroom size has an impact to practice literary works in English classroom.

Table 5. Availability of literary texts in library of the school as a challenge

\begin{tabular}{|l|l|l|l|l|}
\hline No- & Item & Option & No-of respondents & Percentage (\%) \\
\hline 4 & Availability of & very high & 8 & $26 \%$ \\
\cline { 3 - 5 } & literary texts in & High & 7 & $24 \%$ \\
\cline { 3 - 5 } & library & Neutral & 5 & $16 \%$ \\
\cline { 3 - 5 } & & Low & 7 & $24 \%$ \\
\cline { 3 - 5 } & & very low & 3 & $10 \%$ \\
\cline { 3 - 5 } & & Total & 30 & $100 \%$ \\
\hline
\end{tabular}

As explained above, $26 \%$ and $24 \%$ of the respondents responded that availability of literary texts in library is a very high and high challenging factor in the implementations of literary components in English classroom respectively. This shows the scarcity of literary or imaginative works in the library. If there are sufficient imaginative works in the library, both teachers and students can read them and in turn develop their habit of reading. On the other hand, $24 \%$ and $10 \%$ of respondents responded that the availability of literary texts in library is low and very low which means they have observed some imaginative literary works in the library. 16\% of respondents are neutral of the issue. In short, there is no sufficient imaginative works in the library of the school.

\subsection{Analysis of Students' Open-ended Questionnaire}

1. Do you think literary works are important for you? How?

With no reservations, all of the interviewees answered optimistically and they put their reasons as literary works develop their know-how about the culture of other people and to know what is imagined in the story. It is plain that whenever students use different literary texts, they may broaden their knowledge. It also helps them to learn from the experiences of others and it reflects systematic way of teaching. In addition, it empowers their language and literary skills

\section{What genres do or do not you prefer in the classroom and Why?}

I prefer mini-drama, flash fiction, and folktales. This is because the language utilized in comparison to poetry is simple to understand what is depicted for. The language utilized in flash fiction and folktales is simple and helps you to understand the content of it. On the other hand, the way drama performed is also captivating the intention of us so that we prefer it. However, since poems are produced with a chiseled marble of language or most distilled language, it is very difficult to comprehend the message embedded in it.

3. Are you interested with the teachers' implementations of literary works in the English classroom?

Majority of the students are happy with the teachers' implementations of literary components in the English classroom. However, some students are not interested with the teachers' implementations of literary components having the teachers' educational background and capacity as reservations. Teachers need to have trainings on how to handle the class and the issue under scrutiny.

\subsection{Analysis and interpretation of Teacher's Interview}

1. Do you regularly implement literary components found in the text in English classroom? If so, what challenges do you face?

Both teachers believed that they usually implement literary components found in the text in English classroom. This is because the syllabus itself invites to do so this. As depicted in the student text book, we tried to teach the literary components as much as possible. However, we encounter some basic challenges. Among these, the first challenge is students' lack of motivation to learn the lessons in relation to literary components. This is because the students prefer to learn the subject just to pass the examination. Especially, students who came from rural areas face difficulties. This is because of the nature of the language utilized in the production of the literature components. 
This complexity of language especially the language utilized in poems makes them unable to realize the message of texts and they face difficulties in accomplishing tasks given to them. Secondly, the medium itself is another challenge for learners. As stated under the introductory part of this article, English in Ethiopia is delivered as a foreign language. It is not easy for students, even for teachers, to perform well in doing activities related to literary components just like in their mother tongue. Therefore, students feared and demotivated to speak in English and this in turn creates an obstacle in the implementation of literary components in the English classroom. Another challenge is lack of trainings for English teachers. If teachers are given different short term trainings on how to teach literary components or role of literature in the English classroom, they can easily handle and create motivation to students in relation to literary components. The training may also help them on how to select the appropriate materials in line with the level of students. Furthermore, absence of sufficient imaginative works in the library, time allotted for the lessons or the curriculum designed for the text, large classroom size, etc are additional challenges that face the teachers while they implement literature components in English classroom.

\section{What challenges do you think are the severe ones?}

Though there are number of challenges as depicted above, the severe challenges are students' lack of motivation, the language utilized in the literary pieces and the medium of the language that is English. This factors challenge teachers a lot in the implementation of literary components in the English classroom.

\section{Do you think the curriculum is designed with sufficient literary components? And which literary components do you mostly use?}

The teachers absolutely believed that the curriculum is well designed with sufficient literary components. This is also witnessed in document analysis. With teachers' responses and textual analysis of the text, Grade Eight English text book of Ethiopia is designed having sufficient literary components. It consists of different poems, flash fictions or short-short stories, non-fictional writings like biographies of prominent persons, piece of oral traditions like fables, folktales and Essay writings such as narrative, expository and descriptive types etc. In addition, teachers bring their own stories like riddles, role plays and mini-drama in the classroom and trigger students to perform the tasks. The inclusions of these all literary components in the text shows as the curriculum of the text well designed with sufficient literature components. Most of the literary components are also highly preserved with different aspects of the life of Ethiopian people. Among these literary components, the teachers prefer to implement flash fictions, essays and folktales. He language utilized in these genres is ordinary type or simple and plainly stated. However, the language utilized in poems is somewhat difficult to accomplish the tasks following it.

\section{Do you think selection of literary components easy or difficult?}

The selection of literary components is not an easy task. It is very complicated and difficult enough. This is because the level of students has to be critically considered. Not only the level of students but also their social background has to be considered. This needs the teacher to prepare him/herself for proper selection of proper materials. Therefore, to select appropriate materials needs us to be conscious enough.

\section{Conclusions}

The study was conducted at Ambicho Gode primary school grade eight students in particular. The basic findings of this study are grouped in to two ways. The first findings are related to the challenges both teachers and students face in the implementations of literary components in the English classroom and the second findings are related to the literary components employed in the student text book. In relation to challenges teachers and students faced in the implementations of literary components in the English classroom, the following are the basic findings.

$>\quad$ The basic challenges, in relation to the study under scrutiny, are students' lack of motivation to learn, complexity of language employed in literary components, the medium of instruction, and lack of trainings for English teachers.

$>\quad$ In addition, absence of sufficient imaginative works in the library, time allotted for the lessons or the curriculum designed for the text, large classroom size, selection of literary text with the level of students and curriculum of the text are additional factors that affected both teachers and students not to properly implement the literary components in the English classroom.

$>\quad$ The text is designed with different poems, role plays, flash fictions, non-fictional writings like biographies of prominent persons, piece of oral traditions like fables, folktales and Essay writings such as narrative, expository and descriptive types etc.

\section{Reference}

Atefeh Rezanejad, et al. (2015): Down from the Pedestal: Revisiting the Exploit of Literature in EFL Language Classes. International Journal of Applied Linguistics \& English Literature. doi:10.7575/aiac.ijalel.v.4n.2p.158

Brumfit, C J and Carter, R, A (1986). Literature and language. Oxford: Oxford university press.

Cairney, T. H. (1988). Literature in the Classroom: The Making of Literate Learners. In A. Hanzl (Eds.), Literature: a focus for language learning. Melbourne: Australian Reading Association. 
Cao, H.P, (n.d): The Implementation of Literature in Teaching Speaking for Advanced Students, Viet Nam, Ho Chi Minh University of Education.

Carter, R., \& Long, M.N. (1991).Teaching Literature. United States of America: Longman.

Hall, G. (2005): Literature in Language Education .New York: Palgrave Macmillan.

Kheladi Mohammed, (2013): Investigating EFL Learners' Attitudes towards Literature Teaching Methods: Case of $2^{\text {nd }}$ Year LMD Students at the University of Tlemcen, Algeria.

Lazar, G, (1993) Literature and language teaching, Cambridge: Camridge university press.

Littlewood, W. T. (1986): Literature in the School Foreign Language Course. In Burmfit, C. and Carter, R.A. Literature and Language Teaching. Oxford: Oxford University Press.

McKAY, S. L. (1986): Literature in the ESL classroom. In Burmfit, C.J and Carter, R.A. Literature and Language Teaching. Oxford: Oxford University Press.

Maley, A. (1989). Down from the pedestal: Literature as a source. In R. A. Carter \& C. J. Brumfit (Eds.), Literature and the learner: Methodological approaches (pp. 10-23). London: Macmillan.

Moody, H. (1971). The Teaching of Literature. London: Longman.

Rivers, W. M. (1981): Teaching Foreign Language Skills. $2^{\text {nd }}$ ed. Chicago: University of Chicago Press.

Savvidou, C. (2004): An integrated Approach to teaching Literature. TESOL Quarterly 18 (5): 3642

Wagaba William, et al. (2003): English for Ethiopia Student Textbook Grade 8. MK Publishers Ltd, Kampala. 